\title{
Homogenisation of heterogeneous mantle melts in transcrustal plumbing system
}

\author{
FLORIAN BROUILLET ${ }^{1,2}$, LYDÉRIC FRANCE ${ }^{1}$, JANNE \\ M. KOORNNEEF ${ }^{3}$, ADRIEN MOUREY $^{4}$ AND VALENTIN \\ CASOLA $^{1}$
}

${ }^{1}$ Université de Lorraine, CNRS, CRPG

${ }^{2}$ School of Earth and Environmental Sciences, University of St Andrews

${ }^{3}$ Vrije Universiteit

${ }^{4}$ Department of Earth Sciences, University of Hawai'i at Manoa

Presenting Author: fcgb1@st-andrews.ac.uk

Radiogenic isotope signatures of lavas have been used for decades to characterise their mantle sources, and the heterogeneity of the mantle domain. It has been shown recently that the homogeneous signatures of lavas do not record the small-scale mantle heterogeneity that is documented by primitive melt inclusions (MI). The homogenization process of isotopes values through the magma plumbing system remains unconstrained however. Here, we present isotopic data $(\mathrm{Sr}, \mathrm{Nd}$ and $\mathrm{Pb}$ ) of single $\mathrm{MI}$ documenting both primitive and evolved compositions of silicate melts from alkaline Oldoinyo Lengai stratovolcano. We show for the first time that the isotopic variability of the mantle $\left(\mathrm{V}_{\mathrm{Sr}}=57.328\right)$ that is recorded in primitive $\mathrm{MI}\left(\mathrm{V}_{\mathrm{Sr}}=0.501\right)$ is skewed through the magma plumbing system as evolved $\mathrm{MI}\left(\mathrm{V}_{\mathrm{Sr}}=0.096\right)$ populations are rather isotopically homogeneous. We propose that this homogenization proceeds progressively by melt hybridisation upon mixing through the transcrustal plumbing system and is eventually recorded by evolved samples. Our data eventually imply that serious care needs to be taken when bulk lavas are used to infer the composition and variability of the mantle source. 